Brit. J. vener. Dis. (1956), 32, 236

\title{
LATE HEPATIC SYPHILIS*
}

\author{
BY \\ I. A. KELLOCK \\ Senior Medical Registrar \\ AND \\ S. M. LAIRD \\ Director, V.D. Department, Royal Infirmary, Manchester
}

The clinical diagnosis of late hepatic syphilis is never easy, because the role of the Treponema pallidum in the pathogenesis is often difficult to determine accurately. During the tertiary stage, localized gummata may arise in the substance of the liver, and when this process is widespread the resultant fibrosis may produce portal obstruction. In the absence of gummata the syphilitic origin of diffuse cirrhosis must always remain doubtful (Bockus, 1946). In fact, Hahn (1943), quoting Moon (1934), states that, in contrast to true cirrhosis, there is no generalized destruction of the lobular architecture, no nodular regeneration of liver cells, and no generalized increase in fibrous tissue.

The incidence of hepatic syphilis based upon clinical examination alone is unreliable; $\mathrm{McCrae}$ and Caven (1926) recorded 0.2 per cent. of 27,000 persons examined clinically. O'Leary, Greene, and Rowntree (1929) state that during 10 years in the Mayo Clinic the incidence was approximately one in 2,000 admissions. Moore (1944) reports that the clinical diagnosis was made in only 34 of 6,420 patients with late syphilis.

The incidence based upon autopsy studies should be more accurate; McCrae and Caven (1926) give 1.5 per cent. in a series of 3,300 unselected autopsies; Rolleston and McNee (1929), reviewing a total of 53,028 autopsy reports from England and the United States, noted the occurrence of gummata in 194 or 0.36 per cent. of the subjects; and Hahn (1943) reported 0.45 per cent. of late syphilis of the liver from autopsies at the Johns Hopkins Hospital, and the incidence at autopsy among 1,165 adult syphilitics was 4.9 per cent. In 4,880 autopsies, Symmers and Spain (1946) found 314 cases of late acquired syphilis, of which fifty had hepar lobatum, an incidence of approximately 1 per cent. Shapiro and Weiner (1951) studied 79 cases proven at autopsy at the Los Angeles County Hospital from 1928 to 1949. In Manchester, Brockbank (1909), in a study of aortic aneurysm noted in the autopsy records of

\footnotetext{
* Received for publication August 18, 1956.
}

the Royal Infirmary over the previous 40 years, found that 51 of 87 such cases had syphilitic lesions of the liver, of which 36 had cicatricial gummata, seven actual gummata, and twelve gummatous cirrhosis. The recorded clinical features are analysed in the Table.

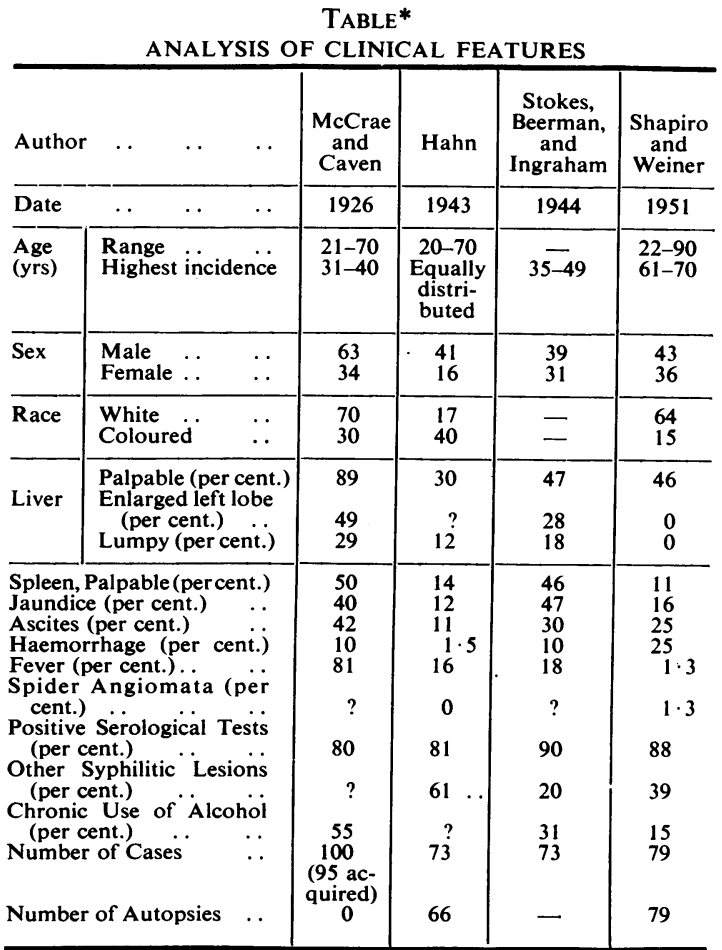

* Modified from Shapiro and Weiner (1951).

Until recently the treatment of late hepatic syphilis was mainly limited to the use of iodides and preparations of bismuth and mercury, the arsphenamines being restricted to those patients without evidence of portal obstruction (Moore 1944).

The therapeutic test has long been utilized as a diagnostic aid, but Hahn (1943) has commented on its limitations. However, provided symptomatic 
improvement is maintained over a prolonged period measured in months or years, this test still has its value. A clinical diagnosis of hepatic syphilis is strongly supported when, after anti-syphilitic treatment, there is clinical improvement manifested by a disappearance of hepatic tumour and jaundice, the non-recurrence of haemorrhage and ascites, and an improvement in liver function tests. The lack of toxicity of penicillin suggests that it should be of value in the treatment of late hepatic syphilis and individual cases so treated have been reported by Tucker and Dexter (1946), Nicol and Terry (1951), and Doyle (1956). Early diagnosis is obviously important and portal obstruction is of serious prognostic significance.

\section{Case Reports}

Case 1, a male aged 43, was first seen in December, 1954 . complaining of swelling of the abdomen for 3 months. He had no pain or dyspnoea, no vomiting, haematemesis, or melena. His appetite was good and he had gained weight. For the past year he had noticed bleeding piles.

Past History. - He had contracted syphilis in 1938, but soon defaulted from treatment. He drank beer occasionally but never spirits, and he had never been jaundiced.

Examination.-He was a well-built man, with a slight icteric tint of the sclerae, apyrexia, good colour of the mucous membranes, and no spider angiomata or palmar erythema.

Cardio-Vascular System.-Pulse rate 100/min., regular; blood pressure 150/80; apex beat $1.5 \mathrm{~cm}$. outside mid-clavicular line; systolic murmur maximal in aortic area; aortic second sound increased.

Respiratory System.-Percussion note impaired; breath sounds diminished over both bases.

Abdomen.-Gross ascites present. After paracentesis abdominis, liver and spleen palpable three fingerbreadths below right and left costal margins respectively.

Central Nervous System.-Very sluggish pupillary reaction to light; loss of deep pain sense in lower limbs; knee jerks exaggerated; plantar responses flexor.

Laboratory Investigations (December, 1954).-

Blood.-Haemoglobin 72 per cent., white blood corpuscles 5,400; normal differential count; platelets 80,000 per c.mm. WR and Kahn test strongly positive.

Liver Function Tests.-Serum albumin 1.8 g. per cent.; serum globulin $5.3 \mathrm{~g}$. per cent.; serum bilirubin $1.0 \mathrm{mg}$. per cent.; thymol turbidity 11 units; serum alkaline phosphatase 14 units (King Armstrong); prothrombin activity 60 per cent. of average normal; bromsulphthalein excretion $(4 \mathrm{~min}$.) $6 \cdot 1$ B.S.P. per $100 \mathrm{ml}$., $(25 \mathrm{~min}$.) 3. 5 B.S.P. per $100 \mathrm{ml}$., (45 min.) 1.7 B.S.P. per $100 \mathrm{ml}$. Ascitic fluid straw-coloured (specific gravity 1010; protein $1 \cdot 15$ g. per cent.; cells mainly lymphocytes).

Cerebrospinal Fluid.-Normal dynamics; cells 42 per c.mm. (35 lymphocytes; 2 monocytes; 5 polymorphs); protein $45 \mathrm{mg}$. per cent.; globulin, opalescence (Pandy), Lange 5543221000, WR positive (tested twice).

Radiology.-Chest $x$-ray and screening showed slight left ventricular hypertrophy, and broadening of mediastinal shadow due to increase in calibre of aorta. Excessive pulsation present, but no localized aneurysm seen. Barium swallow showed no positive evidence of varices.

Treatment.-Low salt, high protein diet with added glucose and vitamin supplements. Mercurial diuretic given intramuscularly twice weekly. Potassium iodide $10 \mathrm{gr}$. three times a day and bismuth intramuscularly $0.2 \mathrm{~g}$. once a week were given for one month, followed by penicillin therapy.

Progress.-The patient steadily improved and, when last seen in February, 1956, had returned to his occupation as a metal grinder and had no pain, vomiting, or ascites. The liver and spleen were smaller, and, although the results of the liver function tests showed no marked change, their trend was towards a return to normal.

Comment.-This patient clearly had diffuse hepatic involvement. That syphilis was the cause is suggested by the concurrent evidence of cardio-vascular and neurosyphilis, the strongly positive serological reactions, and the maintained clinical improvement coincident with anti-syphilitic treatment. There was no evidence in the history of an inadequate diet or of the chronic use of alcohol; nor was there a history of jaundice within the incubation period of syringe-transmitted hepatitis after the few injections given in 1938.

Case 2, a married female aged 58, was originally seen in the surgical out-patient department in March, 1954, complaining of intermittent pain in the right abdomen for 3 years, anorexia, and vomiting with loss of strength and weight, but no haematemesis. There had been constipation but more recently diarrhoea with the passage of blood and a little mucus per rectum.

Examination.-She appeared moderately well, with no pyrexia or spider angiomata, but the liver was found to be enlarged five fingerbreadths below the right costal margin, and was hard, smooth, and tender.

Laboratory Investigations (March, 1954).-Haemoglobin 98 per cent.; white blood corpuscles 9,000 per c.mm. Negative sigmoidoscopy and barium enema.

Operation.-Laparotomy was performed on March 27, 1954, because a carcinoma of the pelvi-rectal junction with hepatic secondaries was suspected. At operation, the liver was seen to be grossly enlarged and cirrhotic, but there was no free fluid. The spleen was normal and no other abnormality was found.

A biopsy of the liver was reported upon as follows:

Naked Eye.-Wedge of brownish tissue, cut curface mottled brown and yellow.

Microscopy.-Lobular pattern indistinct, with irregular fibrosis and lymphocytic infiltration. No evidence of neoplasm (Figure, overleaf).

Further Laboratory Investigations (April, 1954).Blood.-WR and Kahn test strongly positive. Treponemal immobilization test (TPI) positive.

Liver Function Tests. - Serum albumin $3 \cdot 6$ g. per cent.; serum globulin $4.4 \mathrm{~g}$. per cent.; thymol turbidity 0.8 units; prothrombin activity 90 per cent. of average normal; serum alkaline phosphatase 45 units (King Armstrong).

Progress.-In May, 1954, when the patient was transferred to the Special Treatment Centre, the liver was palpable at least four fingerbreadths below the right 
costal margin, and was tender with an irregular edge. The spleen was not palpable, and there were no ascites or haemorrhoids. No abnormal physical signs were detected in the cardio-vascular, respiratory, or central nervous systems. Blood pressure 190/110.

Treatment with penicillin was begun, in addition to a high protein diet with supplementary vitamins.

When last examined in February, 1956, the patient was very well. She had put on weight, the liver edge was palpable only two fingerbreadths below the right costal margin, the spleen was not palpable, and there was no ascites or oedema. 1956). -

Laboratory Investigations (February,

Liver Function Tests.-Serum albumin $4.4 \mathrm{~g}$. per cent.; serum globulin $3 \cdot 2 \mathrm{~g}$. per cent.; serum bilirubin $0.7 \mathrm{mg}$. per cent.; thymol turbidity 0.7 units; serum alkaline phosphatase 25 units (King Armstrong).

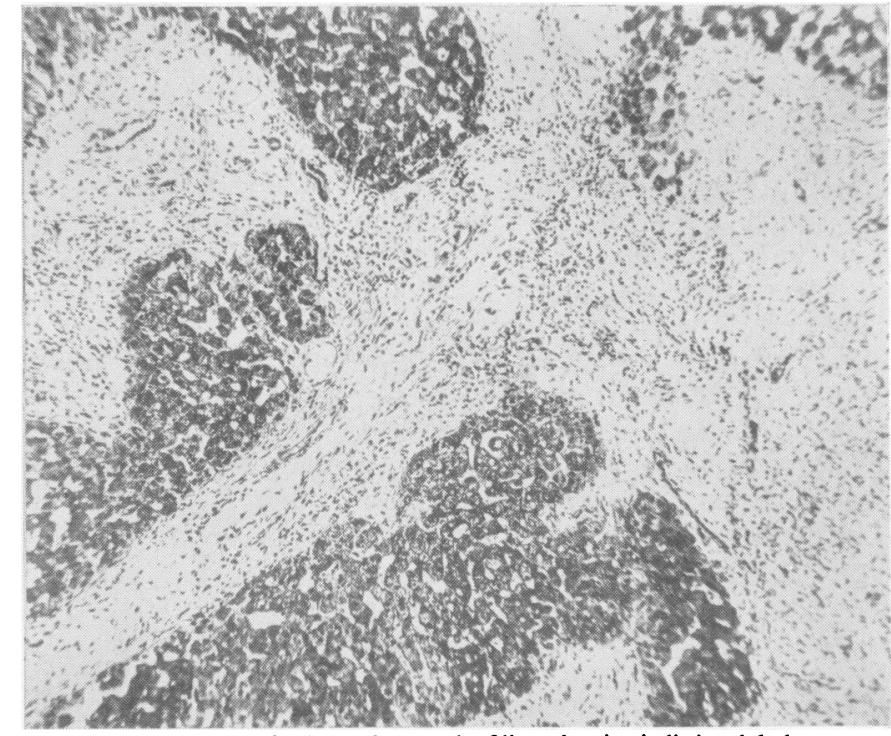

FIGURE.-Case 2, photomicrograph of liver showing indistinct lobular pattern and irregular areas of fibrosis (x75).
Comment.-The finding of cirrhosis at operation led to the serological tests which proved strongly positive. The biopsy appearances suggested the healing of a chronic inflammatory process compatible with late syphilis. The marked clinical improvement with anti-syphilitic treatment, which has now been maintained for nearly 2 years, can be interpreted as a positive therapeutic test. Further support is given by the almost complete return to normal in the results of the liver function tests.

Case 3, a woman aged 55, had had a haematemesis in June, 1947, and had been given 3 pints of blood, having been diagnosed as suffering from a peptic ulcer.

History.-In February, 1948, she had a further severe haematemesis requiring the transfusion of 11 pints of blood, followed by jaundice for 4 days. The liver was palpable four fingerbreadths below the right costal margin and was irregular. Oesophagoscopy in April, 1948, showed large varices in the lower third of the oesophagus. A barium meal showed no evidence of a peptic ulcer. WR and Kahn test were strongly positive; TPI positive. Treatment was started with potassium iodide, but as the patient exhibited iodism only bismuth was maintained. She had further haematemeses in October, 1950, March, 1951, and December, 1951. Before December, 1951, she complained of epigastric and right upper quandrant abdominal pain. Penicillin was first given in January, 1952, and by May, 1955, she had received a total of 38 mega units.

Examination.-In February, 1956, the patient was in good health having had no further haematemeses. She had put on weight, was apyrexial, and showed no evidence of spider angiomata or palmar erythema. The liver was palpable two fingerbreadths below the right costal margin, non-tender, firm, and slightly irregular; the spleen could not be felt, and there was no ascites or oedema. No abnormal physical signs were detected in the cardio-vascular, respiratory, or central nervous systems.

Laboratory Investigations (February, 1956).-

Liver Function Tests.-Serum albumin $4 \cdot 6 \mathrm{~g}$. per cent.; serum globulin $3.6 \mathrm{~g}$. per cent.; serum bilirubin 0.8 mg. per cent.; thymol turbidity $3 \cdot 2$ units; serum alkaline phosphatase 14 units (King Armstrong); prothrombin activity 100 per cent. of average normal.

Radiology.-A barium swallow and meal revealed the persistence of lower oesophageal varices but no abnormality of the stomach or duodenum.

Comment.-The outstanding feature in this patient is the freedom from haematemesis, which has persisted for over 4 years since the beginning of penicillin therapy. This fact, together with the persistence of radiological evidence of oesophageal varices, suggests that the portal hypertension may have been relieved. The only direct evidence of syphilis is serological, and the non-recurrence of haematemesis and general clinical improvement maintained for more than 4 years appear to constitute a positive therapeutic test for syphilis of the liver. Although, unfortunately, tests of liver function had not been carried out before treatment, those in February, 1956 , showed normal values.

Case 4, a male aged 57, was first seen in February, 1948, with a 10 years' history of a chronic gastric ulcer. For 2 weeks he had complained of epigastric pain, anorexia, and the passage of dark urine.

Examination.-He was moderately icteric, the liver edge was palpable two fingerbreadths below the right costal margin and was tender, and in addition, he was found to have small irregular pupils which did not react to light.

Laboratory Investigations (February, 1948).-Urine contained bile pigments. Blood WR and Kahn test strongly positive. 
Cerebrospinal Fluid.-Normal dynamics; protein $30 \mathrm{mg}$. per cent.; cells 2/c.mm.; Lange 4321100000; WR negative

Treatment.-Antisyphilitic treatment with arsenic and bismuth was given between September, 1948, and June, 1950. In March, 1950, he had a moderately severe haematemesis.

Operation.-In June, 1952, he underwent a partial gastrectomy for a chronic gastric ulcer. At operation, the liver was noted to be considerably enlarged and cirrhotic with much bile-stained free fluid in the abdominal cavity.

Progress.-In December, 1954, after an attack of lobar pneumonia, he was still icteric, with ascites and some scrotal and ankle oedema. The liver could not be felt. In July, 1955, when the patient had to be re-admitted to hospital for repeated paracentesis abdominis, the liver and spleen were not palpable.

Laboratory Investigations (July, 1955).-

Blood.-Haemoglobin 86 per cent.; white blood corpuscles 5,500.

Liver Function Tests.-Serum albumin $2 \cdot 6$ g. per cent.; serum globulin $5.7 \mathrm{~g}$. per cent.; serum bilirubin $2.8 \mathrm{mg}$. per cent.; thymol turbidity 19 units; serum alkaline phosphatase 35 units (King Armstrong); prothrombin activity 80 per cent. of average normal.

Progress.-In February, 1956, his general health was moderate. There was no icterus but gross ascites was present. After paracentesis abdominis, the liver was just palpable below the right costal margin but the spleen could not be felt.

\section{Laboratory Investigations (February, 1956).-}

Liver Function Tests.-Serum albumin $2 \cdot 2 \mathrm{~g}$. per cent.; serum globulin $4.6 \mathrm{~g}$. per cent.; serum bilirubin $0.7 \mathrm{mg}$. per cent.; thymol turbidity 12 units; serum alkaline phosphatase 36 units (King Armstrong). Bromsulphthalein (BSP) excretion (4 min.) $6.4 \mathrm{BSP}$ per $100 \mathrm{ml}$., (25 min.) 3.6 BSP per $100 \mathrm{ml}$, (45 min.) $1.6 \mathrm{BSP}$ per $100 \mathrm{ml}$.

Comment.-After an attack of jaundice in 1948, the presence of cirrhosis was established at operation in 1952. The diagnosis of syphilis made in 1948 was based on the presence of neurosyphilis and positive serological tests. Treatment with arsenicals and bismuth over a period of 2 years had obviously failed to arrest the progressive fibrosis of the liver.

There is no history in this patient of inadequate diet, or chronic abuse of alcohol, nor any possibility of syringetransmitted hepatitis before the jaundice noted in 1948. The latter may have been caused by infective hepatitis. Accordingly, syphilis should still be considered in the aetiology in spite of the negative therapeutic test. In the light of recent experience it is perhaps unfortunate that this patient received an arsenical rather than penicillin. The operation in June, 1952, and pneumonia in December, 1954, would both place an added burden on the liver and contribute to the deterioration of liver function.

Case 5, a married woman aged 57, had a cholecystectomy in 1948, and at operation the liver was found to be cirrhotic and enlarged. The spleen was also enlarged and the patient was icteric.
Laboratory Investigations (1948).-

Blood.-Haemoglobin 80 per cent.; Platelets 98,000 c.mm.

Liver Function Tests.-Thymol turbidity 5 units; colloidal gold +; serum alkaline phosphatase 34 units (King Armstrong).

Progress.-During 1949, she noticed increasing swelling of the abdomen and later of the ankles; slight abdominal pain, with occasional nausea and vomiting. Her appetite was poor and there had been a gradual increase in weight. Two months before admission in October, 1954, she had a small haematemesis. Her urine had been dark at times and her stools paler than usual. There was no history of excessive intake of alcohol.

Examination.-She was sallow, but not icteric. Mucosae pale. No spider angiomata or palmar erythema.

Cardiovascular System.-Pulse rate $86 / \mathrm{min}$., regular; blood pressure 170/65; apex beat 5th intercostal space, one inch outside mid-clavicular line; soft systolic murmur maximal in aortic area; early blowing diastolic murmur down left border of sternum; moderate ankle oedema.

Respiratory System.-Percussion note impaired at both lung bases and breath sounds diminished.

Abdomen.-Gross ascites; spleen ballotable; liver not palpable.

Central Nervous System.-No abnormality detected.

Laboratory Investigations (October, 1954).-

Blood.-Haemoglobin 66 per cent.; colour index 0.88; white blood corpuscles $2600 /$ c.mm.; normal differential count; platelets $40,000 /$ c.mm.; Wassermann reaction and Kahn test strongly positive.

Stools.-Benzidine test for blood strongly positive on three occasions.

Liver Function Tests.-Serum albumin 3.7 g. per cent.; serum globulin $3.5 \mathrm{~g}$. per cent.; serum bilirubin $1.0 \mathrm{mg}$. per cent.; thymol turbidity $2 \cdot 3$ units; serum alkaline phosphatase 34 units (King Armstrong); prothrombin activity 72 per cent. of average normal; bromsulphthalein excretion ( $4 \mathrm{~min}$.) $12 \mathrm{mg}$. dye per cent., $(25 \mathrm{~min}$.) $3 \mathrm{mg}$. dye per cent., (45 min.) $1.5 \mathrm{mg}$. dye per cent.

Ascitic Fluid.-Straw coloured; sterile; protein $1.6 \mathrm{~g}$. per cent.; cells mainly lymphocytes.

Cerebrospinal Fluid.-Normal dynamics; protein 25 mg. per cent.; Lange 0000000000 ; WR negative.

Radiology.-Barium swallow showed varicosities in lower and middle thirds of oesophagus; stomach and duodenum, no abnormality.

Treatment.-Low-salt diet, with added glucose and vitamins and a mercurial diuretic twice weekly. In addition, the patient was given potassium iodide and a bismuth preparation for one month, followed by penicillin, in December, 1954.

Progress.-About a week before antisyphilitic treatment was begun, the patient had a further haematemesis and melaena. From January, 1955, to the time of her death in September, 1955, she had to be re-admitted several times for paracenteses. There were, however, no further haematemeses during the last 10 months.

Laboratory Investigations (July, 1955)-

Liver Function Tests.-Serum albumin $2.6 \mathrm{~g}$. per cent.; serum globulin $3.0 \mathrm{~g}$. per cent.; serum bilirubin $5.0 \mathrm{mg}$. per cent. 
Death.-During 1955 there was gradual deterioration in her condition and she died in hepatic coma in September, 1955. Autopsy not permitted.

Comment.-The presence of cirrhosis was established at operation in 1948 and progressed with clinical evidence of portal hypertension until the fatal outcome from hepatic failure in September, 1955. A diagnosis of syphilis in December, 1954, was based on the cardiovascular involvement and positive serological tests.

Treatment with potassium iodide and bismuth, followed later by penicillin, did not influence the failing liver function which was already far advanced. The absence of other aetiological factors raises the possibility of hepatic syphilis.

Case 6, a man aged 64, was first seen in December, 1954. For 3 months he had had symptoms which led to a diagnosis of diabetes mellitus. There had been neither haematemesis, melaena, or jaundice. Primary syphilitic infection probably occurred in 1916, but no treatment was given.

Examination.-Liver palpable 4 inches below the right costal margin and although non-tender was nodular. Minimal ascites was also present clinically. The spleen was not felt. The pupils were slightly irregular and their reaction to light was sluggish; apart from these pupillary changes no other clinical evidence of syphilis was found. No spider angiomata were present.

Laboratory Investigations (December, 1954).-

Blood.-WR and Kahn test positive.

Cerebrospinal Fluid.-Normal dynamics; cells 2 lymphocytes per c.mm.; protein $30 \mathrm{mg}$. per cent.; WR negative. Liver Function Tests.-Plasma proteins, serum alkaline phosphatase, and thymol turbidity showed normal values.

Treatment.-The diabetes was controlled by diet and insulin. For the syphilitic infection, penicillin was begun in hospital, and continued subsequently in the out-patients clinic.

Progress.- He has been seen at intervals and his general condition has remained satisfactory. In December, 1955, a year after treatment was begun, the liver was palpable half an inch below the costal margin and neither nodules nor ascites were then noted.

Comment.-It was known that this patient had been a moderately heavy drinker of alcohol, and, in fact, continued to take alcohol against medical advice. There was no evidence that his previous diet was inadequate, and his insulin and diabetic diet have been adjusted to ensure sufficient protein and carbohydrate.

The diagnosis of syphilis was based on the pupillary changes and positive serological tests.

The improvement, maintained after one year, in the patient's general health, the reduction in the size of the liver, and the non-recurrence of ascites constitute a positive therapeutic test and suggest that syphilis played at least some part in the hepatomegaly.

Case 7, a married woman aged 60, first attended hospital in April, 1941, complaining of attacks of abdominal pain, occurring every 3 to 4 weeks and lasting about 4 days, during the past 3 years. She vomited occasionally, but there was no haematemesis. Her appetite was good and her weight steady.

Examination.-A hard mass was palpable below the right costal margin. It was originally thought that this mass was an enlarged gall bladder. A straight $x$-ray and cholecystogram, however, showed no obvious evidence of gall stones and a normally functioning gall bladder. Further examination showed that the swelling involved the lower edge and anterior surface of the liver. It was tender, hard, and moved well on respiration. No other abnormality was found. The blood Wassermann reaction and Kahn test were strongly positive.

Treatment.-Potassium iodide was begun in December, 1941, and increased to $30 \mathrm{gr}$. three times a day. The patient felt better, the pain disappeared, and she was discharged home to continue on potassium iodide. There was no appreciable change in the size of the palpable mass in the right upper quandrant when she was seen one year later. After 7 years, in January, 1948, she came to the special treatment centre where bismuth and penicillin treatment was given.

Progress.-When last seen in November, 1955, the patient was in excellent health and no abdominal mass was palpable.

Comment.-This patient differs from the others in the present series in showing local rather than diffuse hepatic involvement. The positive serological tests, the disappearance of the hepatic tumour after treatment, and the excellent health maintained over 13 years, all favour a diagnosis of localized gumma of the liver.

\section{Discussion}

Syphilis is now rarely considered in the differential diagnosis of liver disease. While this no doubt reflects the beneficial effects of modern therapy in the early stages, it is also partly due to the paucity of symptoms and the absence of physical signs caused solely by syphilis of the liver. The latter clinical difficulties are illustrated by our cases, all of which however, with the exception of Case 7, had generalized enlargement of the liver associated with positive serological evidence of syphilis. In cases with ascites, the degree of hepatomegaly is best assessed after paracentesis. In non-syphilitic diseases of the liver with disturbance of the plasma proteins, the standard serological tests may give false-positive reactions (Geier and Doepfmer, 1952) but in such cases a negative Treponemal Immobilization test (TPI) should prevent a mistaken diagnosis of syphilis. Despite the broad statement by Bockus (1946), disputed by Shapiro and Weiner (1951), that hepatic syphilis is seldom found in patients with neurosyphilis or vascular syphilis, we feel that evidence of syphilis of other parts of the body, particularly cardiovascular and central nervous systems, is useful in confirming past infection with syphilis. 
Stokes, Beerman, and Ingraham (1944), in a series of 419 patients, found that 33 of forty patients with enlargement of the liver had positive blood Wassermann reactions, and that 17 of twenty patients with both hepatic and splenic enlargement had positive blood Wassermann reactions. From our limited experience, we would support their suggestion that serological tests for syphilis should be a routine investigation in patients with hepatic and splenic enlargement.

Having established the presence of syphilis in a patient with hepatomegaly, one must then try to decide whether these two findings are related or not. Careful inquiry will usually indicate whether dietary deficiency or the chronic use of alcohol could be significant, but it should be remembered that these factors may be associated environmentally with exposure to syphilitic infection. In patients with a history of previous jaundice, it is important to eliminate the possibility of this having been due to syringe-transmitted hepatitis complicating the treatment of early syphilis, as some such cases are known to have progressed to cirrhosis and hepatic failure. In nutritional cirrhosis, the incidence of spider angiomata has been given as 76 per cent. (Patek, Post, and Victor, 1940); Hahn (1943) observed none in his cases and Shapiro and Weiner (1951) found that spider angiomata could be assigned solely to hepar lobatum in only one of 76 cases. None of our seven cases had spider angiomata.

Tests of liver function are of no value in differential diagnosis (Bockus, 1946) and histological study after laparotomy or needle biopsy has only limited value (Nicol and Terry, 1951; Doyle, 1956, Read and Doig, 1956). When involvement of the liver is localized, needle biopsy may only obtain normal tissue, and even when the gumma is needled the biopsy findings may be inconclusive (Viranuvatti and Kochaseni, 1953). Our own specimen (Case 2), although obtained at laparotomy, was not diagnostic.

A positive therapeutic test is probably the most valuable single procedure in confirming an association between syphilis and liver enlargement. The significant point in this test is the initial clinical improvement which must, however, be maintained over an observation period of months or preferably years (Hahn, 1943).

In single cases of late hepatic syphilis treated with penicillin, good results have been reported by Tucker and Dexter (1946), Nicol and Terry (1951), and Doyle (1956). In Cases 1, 2, 3, and 6 of our own series, a positive therapeutic test followed the use of penicillin. In Case 3, it is interesting to observe that no further haematemeses have occurred for 4 years after the start of penicillin therapy, although oesophageal varices are still demonstrable radiologically.

In Case 5, penicillin did not arrest the increasing liver failure, and a similar trend in Case 4, who did not receive penicillin, followed the use of arsphenamines. In both cases it is probable that fibrosis of the liver was already widespread before treatment was begun, and this emphasizes the need for early diagnosis. The relative freedom from toxicity of penicillin as compared with the arsenicals probably makes it the drug of choice in the treatment of hepatic syphilis. However, in localized gumma (Case 7), a satisfactory therapeutic response was obtained with iodides alone, although bismuth and penicillin were given later.

In localized gumma of the liver, the prognosis after treatment with iodides and penicillin should be satisfactory. With diffuse liver involvement the prognosis will be influenced by the degree of fibrosis at the time of treatment and subsequent portal obstruction.

\section{SUMmaRY}

(1) The incidence, clinical features, diagnosis, treatment, and prognosis of late hepatic syphilis are discussed.

(2) Six probable cases are described, together with one case of localized gumma of liver.

(3) In cases presenting with hepatic enlargement, syphilis should still be considered and serological tests carried out.

(4) A positive therapeutic test is probably the most valuable single procedure in confirming the association between syphilis and liver enlargement; penicillin appears to be the drug of choice.

We would like to thank Dr. Smith, Department of Pathology, University of Manchester, for the photomicrograph.

\section{REFERENCES}

Bockus, H. L. (1946). "Gastro-Enterology", vol. 3. Saunders, Philadelphia and London.

Brockbank, E. M. (1909). Med. Chron., 50, (4th ser., 17), 319.

Doyle, J. O. (1956). Brit. med. J., 1, 96.

Geier, F., and Doepfmer, R. (1952). Dtsch med. Wschr., 77, 1254

Hahn, R. D. (1943). Amer. J. Syph., 27, 529.

McCrae, T., and Caven, W. R. (1926). Amer. J. med. Sci., 172, 781.

Moon, - (1934). Quoted by Hahn (1943).

Moore, J. E. (1944). "The Modern Treatment of Syphilis", 2nd Ed. Bailliere, Tindall \& Cox, London.

Nicol, C. S., and Terry, R. B. (1951). British Journal of Venereal Diseases, 27, 20.

O'Leary, P. A., Greene, G. H., and Rowntree, L. G., (1929). Arch. intern. Med., 44, 155

Patek, A. J., Jr., Post, J., and Victor, J. C. (1940). Amer. J. med. Sci., 200,341 .

Read, L., and Doig, A. (1956). Brit. med. J., 1, 458.

Rolleston, H., and McNee, J. W. (1929). "Diseases of the Liver, Gall-bladder and Bile-ducts", 3rd Ed. Macmillan, London.

Shapiro, E., and Weiner, H. (1951). Amer. J. med. Sci., 222, 494.

Stokes, . H. Beerman, H. and Ingraham, N. R. (1944). "Modern Clinical Syphilology", 3rd Ed. Saunders, Philadelphia and London.

Symmers, D., and Spain, D. M. (1946). Arch. Path. (Chicago), 42, 64. Tucker, H. A., and Dexter, D. D. (1946). Arch. intern. Med., 78, 313. Viranuvatti, V.,, and Kochaseni, S. (1953). Rev. Gastro-ent., 20, 118. 